\title{
Avaliação da capacidade de realizar sprints repetidos no futebol
}

\author{
Henrique Bortolotti ${ }^{1,2,3,4}$ \\ Bruno Natale Pasquarelli ${ }^{3}$ \\ Lúcio Flávio Soares-Caldeira ${ }^{2,5}$ \\ Leandro Ricardo Altimari, \\ Fábio Yuzo Nakamura ${ }^{2,3}$ \\ ${ }^{1}$ GEPESINE - Grupo de Estudo e Pesquisa em Sistema Neuromuscular e Exercício, \\ Centro de Educação Física e Esporte da UEL, Londrina, PR, Brasil \\ ${ }^{2}$ GEAFIT - Grupo de Estudo das Adaptações Fisiológicas ao Treinamento, Centro de \\ Educação Física e Esporte, UEL, Londrina, PR, Brasil \\ ${ }^{3}$ CEFE - Centro de Educação Física e Esporte da UEL, Londrina, PR, Brasil \\ ${ }^{4}$ GEPEMENE - Grupo de Estudo e Pesquisa em Metabolismo, Nutrição e Exercício, \\ Centro de Educação Física e Esporte da UEL, Londrina, PR, Brasil \\ ${ }^{5}$ Universidade Norte do Paraná - UNOPAR, Londrina, PR, Brasil
}

\begin{abstract}
Resumo: A maioria dos esportes coletivos (ex.: futebol, basquete, handebol) tem como característica a intermitência, flutuando entre breves períodos de esforços máximos ou próximos ao máximo seguidos de períodos e formas de recuperação. Alguns autores têm proposto diversos testes que tem por finalidade mensurar a capacidade desses atletas em realizar esforços repetidos máximos (RSA), a qual estaria diretamente relacionada aos momentos decisivos durante partida. Dessa forma, o presente estudo teve como objetivo descrever os diferentes protocolos de testes para avaliar a RSA em jogadores de futebol, com base em artigos originais e algumas revisões levantadas na base de dados Medline. Diante dos achados, sugerimos a utilização de quatro protocolos, dois envolvendo sprints lineares (AZIZ et al., 2008; REILLY, 2001) e dois utilizando sprints com mudanças de direção (BANGSBO, 2008; IMPELLIZZERI et al., 2008) para avaliação da RSA em jogadores de futebol, gerando importantes parâmetros de desempenho, que permitem ainda a elaboração de programas de treinamento para a melhora dessa capacidade. Recomendamos ainda, a utilização do tempo médio e/ou total como uma medida geral da capacidade de realizar sprints repetidos e as parciais de tempo de cada sprint para identificar possíveis pontos fortes e fraco de cada atleta.
\end{abstract}

Palavras-chave: Futebol. Esportes coletivos. Sprints. Desempenho motor.

\section{Repeated sprint ability evaluation in soccer}

\begin{abstract}
The most of team sports (soccer, basketball, handball) is characterized by intermittency, fluctuating between brief periods of maximum effort or near the maximum followed by periods and forms of recovery. Some authors have proposed several tests to measure the ability of these athletes to perform repeated sprints (repeated sprint ability - RSA), which would be directly related to the decisive moments during match. Then, this study aimed to describe the different test protocols to assess RSA in soccer players, based on original articles and reviews selected in some databases (Medline). Therefore, we suggest four protocols, two involving sprints linear (Aziz et al. 2008; Reilly, 2001) and two involving sprints with changes of direction (Bangsbo, 2008; Impellizzeri et al., 2008) to evaluate the RSA in soccer players, generating important performance parameters, which allow to develop training programs to improve that capacity. We also recommend the use of average and/or total time as a general measure of ability to perform repeated sprints and the partial duration of each sprint to identify strengths and weakness of each athlete.
\end{abstract}

Key Words: Soccer. Team sports. Sprints. Motor performance.

\section{Introdução}

Os padrões de movimentos em grande parte dos esportes coletivos são de natureza intermitente, alternando breves períodos de esforços máximos ou próximos do máximo, seguidos de diferentes períodos e formas de recuperação (ex.: futebol, handebol, rugby, basquete, badminton, tênis, etc) (GLAISTER, 2005; SPENCER et al, 2005).

Capacidade de realizar sprints repetidos (RSA) tem sido definida como a capacidade de realizar repetidamente sprints de curta duração (OLIVER et al., 2007). Este padrão de atividade tem sido 
observado em diversas modalidades esportivas intermitentes, particularmente as coletivas (SPENCER et al., 2005, GLAISTER, 2005). Na tentativa de avaliar correlatos fisiológicos envolvidos na capacidade de realizar sprints repetidos, alguns testes tem sido propostos. Os pesquisadores sugerem que as informações provenientes destes testes possam melhorar o entendimento acerca da influência de algumas capacidades físicas sobre o desempenho em modalidades esportivas com características intermitentes (SPENCER et al., 2005). Alguns destes protocolos foram baseados em dados gerados por meio da análise dos padrões de movimento durante partidas através de imagem de vídeos (time-motion analysis), na tentativa de melhor representar as ações de jogo (SPENCER et al., 2005; GABBETT e MULVEY, 2008). Porém, diferentes protocolos têm sido usados para investigar a RSA em esportes coletivos, com diferenças no padrão de corrida (linear e com mudanças de direção), duração do esforço, número de repetições e tipo de recuperação.

No futebol, as ações predominantes são aeróbias. Em um estudo recente, Bradley et al. (2009) mostraram uma razão de 1:3 entre a distância percorrida em alta intensidade (> 14,4 $\mathrm{km} / \mathrm{h}$ ) em relação às corridas em baixa e moderada intensidade. Entretanto, as ações determinantes em uma partida têm maior contribuição do sistema anaeróbio e acontecem repetidamente durante uma partida. Dessa forma, a RSA tem sido associada de forma decisiva ao desempenho em diversas modalidades esportivas (DUPONT et al., 2005).

Nesse sentido, demonstrou-se uma associação positiva entre o desempenho em testes de sprints repetidos (RSAt) e as distâncias percorridas em alta intensidade $\left(>19,8 \mathrm{~km} \cdot \mathrm{h}^{-1}\right)$ e em sprint $\left(>25,2 \mathrm{~km} \cdot \mathrm{h}^{-1}\right)$ durante uma partida (RAMPININI et al., 2007). Da mesma forma, as variáveis de desempenho obtidas no RSAt também foram sensíveis em discriminar jogadores de diferentes níveis competitivos e

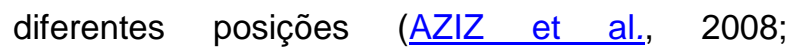
IMPELLIZZERI et al., 2008).

Sendo assim, na tentativa de auxiliar em uma análise comparativa sobre os estudos que investigaram a relação entre determinantes de desempenho e testes de sprints no futebol, esta revisão teve como base em artigos originais e algumas revisões levantadas nas principais bases de bases de dados (Medline e Scopus). O objetivo foi descrever os diferentes protocolos de testes para avaliar a RSA em jogadores de futebol e seu suporte fisiológico.

\section{Determinantes fisiológicos para o desempenho em RSAt}

Durante um único sprint máximo (5-6 segundos), é relatado que a creatina fosfato (PCr) contribui em aproximadamente $50 \%$ do total do fornecimento energético para a ressíntesse de adenosina trifosfato (ATP) (Figura 1). Contudo, a contribuição da $\mathrm{PCr}$ durante sprints repetidos é amplamente determinada pelo magnitude dos estoques da PCr que são restabelecidos durante os períodos de intervalo (GLAISTER, 2005).

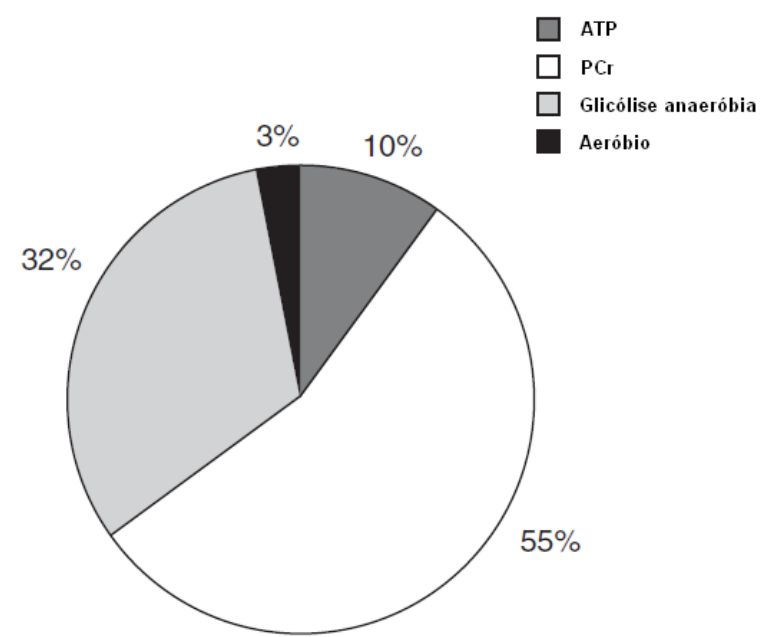

Figura 1. Contribuição estimada dos sistemas energéticos em um sprint de $3 \mathrm{~s}$. ATP = adenosina trifosfato, $\mathrm{PCr}=$ creatina fosfato. (Adaptado de SPENCER et al., 2005)

Durante um sprint máximo, com rápida queda das concentrações da PCr, há um aumento na ativação da glicólise para manter as taxas de turnover do ATP, para compensar essa queda. Dessa forma, há elevação dos níveis de lactato sanguíneo, associados com um aumento das concentrações dos íons de hidrogênio $\left(\mathrm{H}^{+}\right)$, que tem sido muitas vezes implicado como a causa da fadiga. Durante a recuperação, a glicólise é "desligada" e o pH tende a retornar ao níveis de repouso, após aproximadamente nove minutos do término da atividade.

A taxa da atividade glicolítica para ressíntese do ATP é regulada com a interação entre vários processos metabólicos, sendo que durante esforços intermitentes máximos e progressivos as mudanças metabólicas do ambiente interno sofrem uma gradual inibição da glicólise em sprints repetidos. Isso pode ser explicado pelo 
fato de que a glicólise é comprometida pela depleção progressiva dos estoques de glicogênio associada a esse tipo de trabalho. Outra sugestão é que a glicólise é comprometida pela queda progressiva do $\mathrm{pH}$, uma vez que o acúmulo de $\mathrm{H}^{+}$ inibe a fosfofrutoquinase (PKF), que é a enzimachave regulatória das enzimas da glicogenólise e da glicólise. A terceira possibilidade é que a glicólise é inibida pelo acúmulo do citrato no citosol, que exerce um efeito inibitório sobre a PKF.

Existe um atraso para que o $\mathrm{VO}_{2}$ comece a ser determinante em esforços curtos e intensos. Porém, esse atraso pode ser compensado pelo oxigênio ligado a mioglobina $\left(\mathrm{MbO}_{2}\right)$, que pode suprir a demanda de oxigênio no início do exercício. As concentrações de mioglobina no músculo humano são de aproximadamente 2 mmol. $\mathrm{kg}^{-1}$ de músculo seco. Esses estoques de oxigênio são dessaturados no início do exercício, com rápida queda da pressão parcial intracelular de oxigênio. Em uma intensidade suficiente para extrair o $\mathrm{VO}_{2}, \quad$ a $\mathrm{MbO}_{2}$ é dessaturada em aproximadamente $50 \%$ dos valores de repouso em 20 segundos, porém a sensibilidade da dessaturação da $\mathrm{MbO}_{2}$ em exercícios intensos ainda apresenta controvérsias.

Durante os seis primeiros segundos até 30 segundos de um único sprint máximo, a contribuição aeróbia para ressíntese do ATP é muito pequena $(<10 \%)$, porém em sprints repetidos o nível da contribuição aeróbia para a ressíntese do ATP aumenta progressivamente devido a possibilidade de elevação e aceleração do $\mathrm{VO}_{2}$. Por exemplo, durante a recuperação de um trabalho curto e de alta intensidade $\mathrm{O}^{\mathrm{VO}_{2}}$ continua elevado, para tentar reestabelecer 0 metabolismo às condições de repouso através dos processos que restauram os estoques da $\mathrm{MbO}_{2}$, promovem ressíntesse da $\mathrm{PCr}$, metabolismo de lactato e remoção intracelular de $\mathrm{Pi}$. Como os sprints subsequentes são realizados antes que $\mathrm{o} \mathrm{VO}_{2}$ retorne ao níveis de repouso, o $\mathrm{VO}_{2}$ será sempre elevado em sprints repetidos.

Apesar do aumento progressivo da contribuição aeróbia na ressíntese do ATP, em sprints repetidos, sua contribuição é considerada muito pequena no que diz respeito à demanda total de energia. Portanto, o papel do metabolismo aeróbio no trabalho de sprints repetidos está ligado principalmente ao reestabelecimento da homeostase durante os períodos de recuperação.
O processo de fadiga em sprints repetidos tem sido amplamente investigado; porém, existem muitas lacunas a serem preenchidas. Em esforços repetidos máximos (múltiplos sprints) o processo de fadiga tem sido associado primariamente a mudanças no ambiente intramuscular. A falta de oferta de ATP para os filamentos contráteis de actina e miosina, bomba sódio-potássio $\left(\mathrm{Na}^{+} / \mathrm{K}^{+}\right)$e consumo de íons de cálcio $\left(\mathrm{Ca}^{2+}\right)$ pelo retículo sarcoplasmático são alguns dos fatores que podem limitar 0 desempenho.

Dessa forma, a tarefa realizada influencia diretamente no desempenho em esforços desta natureza. A duração ou razão entre esforço e pausa e o tipo de recuperação (ativa ou passiva) que, dessa forma, modulam o volume e a intensidade, podem gerar diferentes respostas de desempenho (CASTAGNA et al., 2008). Estes fatores, por sua vez, exercem sua influência principalmente sobre a capacidade de ressíntese de ATP e creatina fosfato (PCr) (SPENCER et al., 2005; GLAISTER, 2005). Além disso, a produção de metabólitos associados à acidose metabólica e nível de aptidão aeróbia também parecem influenciar o desempenho neste padrão de esforço (GLAISTER, 2005).

\section{Testes de sprints repetidos no futebol}

Os testes para jogadores de futebol podem abranger componentes técnicos, táticos, psicológicos e, sobretudo, físicos. No que concerne à avaliação dos componentes físicos, Bangsbo (2008) indica razões para se realizar os testes: a) estudar o efeito de um programa de treinamento; b) motivar os jogadores a treinar com maior empenho; c) dar aos jogadores resultados objetivos do seu estado de treinamento; d) conscientizar os jogadores dos objetivos do treinamento; e) avaliar se um jogador está preparado para jogar uma partida de competição, e; f) planificar programas de treinamento de curto, médio e longo prazo.

Dessa forma, é necessário que os testes atendam as demandas da modalidade e que suas condições se reproduzam durante o jogo.

$\mathrm{Na}$ tentativa de avaliar os correlatos fisiológicos envolvidos na capacidade de realizar sprints repetidos, alguns testes tem sido propostos. A Tabela 1 descreve diferentes protocolos encontrados na literatura para avaliação desta capacidade em jogadores de 
futebol. De forma geral, tais protocolos diferem desde a distância dos sprints, número de repetições, duração do intervalo entre os sprints, caráter da recuperação (ativa e passiva) e tipo de corrida (linear e com mudanças de direção).

Tabela 1. Estudos que utilizaram protocolos de testes de RSA para jogadores de futebol.

\begin{tabular}{|c|c|c|c|c|c|}
\hline Estudo & $\mathbf{N}$ & $\begin{array}{l}\text { Distância do } \\
\text { sprint (m) }\end{array}$ & $\begin{array}{l}\text { Número de } \\
\text { repetições }\end{array}$ & $\begin{array}{c}\text { Duração da } \\
\text { recuperação (s) }\end{array}$ & $\begin{array}{c}\text { Tipo de } \\
\text { recuperação }\end{array}$ \\
\hline Abrantes (2004) & 146 & 34,2 & 7 & 25 & Ativa \\
\hline Aziz et al. (2000) & 40 & 40 & 8 & 30 & Ativa \\
\hline Aziz et al. (2007) & 53 & 20 & 6 & 20 & $\mathrm{NR}$ \\
\hline Aziz et al. (2008) a & 121 & 20 & 6 & 20 & Ativa \\
\hline b & & 20 & 8 & 20 & Ativa \\
\hline Bangsbo (1994)* & NR & 34,2 & 7 & 25 & Ativa \\
\hline Ferrari Bravo et al. (2008) & 42 & $40(20+20)$ & 6 & 20 & Passiva \\
\hline \multirow[t]{2}{*}{ Glaister et al. (2008) } & 10 & 30 & 12 & 35 & NR \\
\hline & 10 & 30 & 12 & 65 & NR \\
\hline Impellizzeri et al. (2008)* & 108 & $40(20+20)$ & 6 & 20 & Passiva \\
\hline \multirow[t]{2}{*}{ Meckel et al. (2009) } & 33 & 40 & 6 & 30 & Ativa \\
\hline & & 20 & 12 & 20 & Ativa \\
\hline Mujika et al. (2000) & 17 & 15 & 6 & 24 & NR \\
\hline Oliver $(2006)^{\star}$ & 12 & 10 e 30 & 7 & 25 & Ativa \\
\hline Psotta $(2003)^{\star}$ & 29 & 20 & 10 & 20 & NR \\
\hline Rampinini (2007) & 18 & $40(20+20)$ & 6 & 20 & Passiva \\
\hline Rabelo (2009) & 73 & 35 & 6 & 10 & Passiva \\
\hline Reilly (2001) & NR & 10 e 30 & 7 & 25 & Ativa \\
\hline Zagatto et al. (2009)* & 40 & 35 & 6 & 10 & Passiva \\
\hline Wragg et al. (2000)* & 7 & 34,2 & 7 & 25 & Ativa \\
\hline
\end{tabular}

* testes que atenderam a um ou mais critérios de validação

NR $=$ Não reportado no estudo

Considerando que no futebol as ações ocorrem de maneira estocástica, e variações na intensidade e direção das corridas são freqüentes durante uma partida, a maior parte dos protocolos propostos não têm sido estabelecidos de maneira que possa replicar fielmente as ações realizadas durante o jogo. Alguns testes descartam a natureza de corridas multidirecionais e com recuperação ativa entre esforços de alta intensidade, presente nas modalidades com características intermitentes, como o futebol (WRAGG et al., 2000). Além do mais, apesar da grande quantidade de testes encontrados, poucos foram validados de acordo com os pressupostos descritos por Impellizzeri e Marcora (2009), e muitos dos que foram validados, atenderam parcialmente aos critérios principais estabelecidos de: 1) modelação conceitual do teste; 2) validade; 3) reprodutibilidade, e; 4) responsividade (IMPELLIZZERI e MARCORA, 2009). Na Tabela 1 estão destacados os protocolos que foram validados para avaliação da capacidade de realizar sprints repetidos.

Dessa maneira, recomendamos fortemente que forneça parâmetros indicativos do estado de treinamento do atleta. Tendo em vista os pressupostos de validade lógica e de constructo, é necessário escolher os testes que mais se aproximem da situação do jogo e que, de alguma forma, forneça parâmetros indicativos do estado de treinamento do atleta. Sendo assim, sugerimos a utilização de quatro protocolos; dois envolvendo sprints lineares (AZIZ et al., 2008; REILLY, 2001, Figura 2) e dois utilizando sprints com mudanças de direção (BANGSBO, 2008; IMPELLIZZERI et al., 2008, Figura 3) que acreditamos avaliar a capacidade de realizar sprints repetidos em jogadores de futebol. 


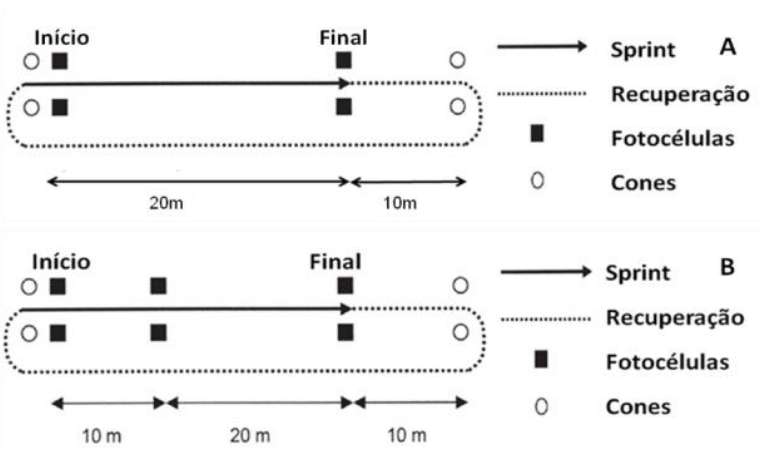

Figura 2. Desenho esquemático dos testes de sprints repetidos lineares: A) Aziz et al. (2008a); B) Reilly (2001).

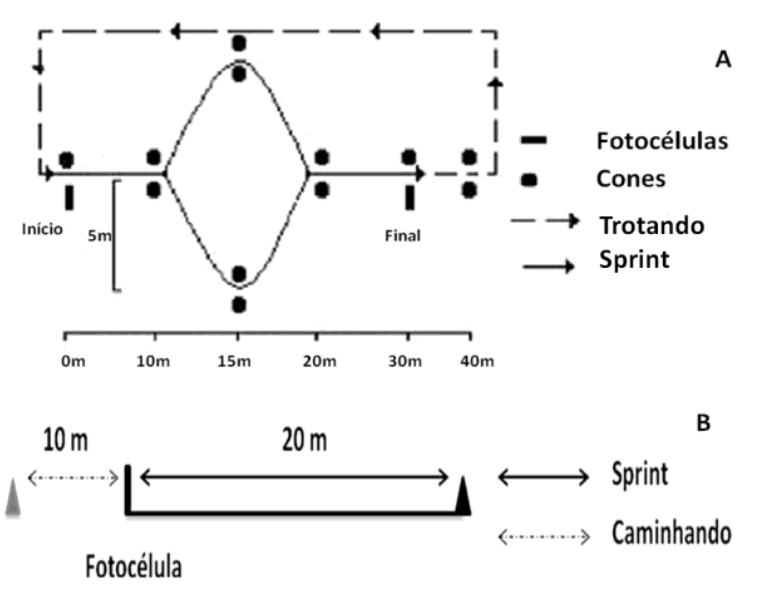

Figura 3. Desenho esquemático dos testesde sprints repetidos com mudança de direção: $A$ ) Bangsbo (2008); B) Impellizzeri et al. (2008).

\section{Utilização dos resultados nos testes de sprints repetidos}

Tão importante quanto o rigor na aplicação de um teste é a interpretação de seus resultados. Algumas informações tem sido utilizadas como indicativo de desempenho em testes de sprints repetidos. Serão discutidas no presente estudo: 0 tempo médio dos sprints, tempo total de todos os sprints, tempo do melhor sprint e os índices de fadiga.

No estudo de Rampinini et al. (2007), foi demonstrado que o tempo médio dos seis sprints $(6 \times 20+20 \mathrm{~m})$ teve uma correlação de $r=-0,65$ com a distância percorrida em sprints $(>25,2$ $\mathrm{km} \cdot \mathrm{h}^{-1}$ ) e $\mathrm{r}=-0,60 \mathrm{com}$ a distância percorrida em alta intensidade $\left(19,8\right.$ a 25,2 km. $\left.{ }^{-1}\right)$. Dessa maneira, os autores concluíram que tais achados contribuíram para obtenção da validade de constructo do teste de sprints repetidos, estando este relacionado ao desempenho de jogadores de futebol de elite durante uma partida (RAMPININI et al., 2007). No entanto, cabe ressaltar que correlações moderadas não permitem a utilização do teste como preditor de desempenho no jogo (RAMPININI et al., 2007).

Outra medida utilizada é o tempo total. Aziz et al. (2008), mostraram que esse indicativo, ou seja, a soma dos tempos de todos os sprints, foram capazes de diferenciar grupos com diferentes níveis competitivos e posições, suportando assim a validade de constructo do teste.

Fortes correlações são encontradas entre o tempo médio e tempo total (RABELO, 2009). No entanto, alguns estudos têm reportado que essas medidas podem ser limitadas quando influenciadas pela tentativa dos indivíduos se pouparem durante o teste (pacing) e, nesse sentido, a validade dessa informação ficaria prejudicada (OLIVER et al., 2006).

Outra medida importante seria o tempo do melhor sprint da série. Visto que um jogador pode ter um excelente resultado quando analisado pelo tempo médio e/ou tempo total, por ser pouco suscetível à fadiga, ao mesmo tempo sua capacidade de realizar esforços máximos pode ser insuficiente em relação ao grupo. Dessa forma, o melhor sprint representa uma alternativa para avaliação da velocidade "pura" do jogador.

Comumente, os melhores tempos são obtidos no $1^{\circ}$ e $2^{\circ}$ sprints, e os piores nos dois últimos. A relação entre o melhor e o pior tempo fornece um indicativo de queda de desempenho. Muitos estudos têm utilizado índices de fadiga como indicativo de queda de desempenho no teste. Dois estudos de Glaister et al. (2004; 2008) mostraram que, embora haja diferenças na magnitude do índice de fadiga quando comparados diferentes modelos, o mesmo constitui uma medida válida para analisar 0 desempenho em testes de sprints repetidos. Entretanto, posterior aos estudos citados anteriormente, Oliver et al. (2009) mostraram que a utilidade dos índices de fadiga é duvidosa e que outras medidas como: tempo médio, tempo total, melhor tempo e tempos individuais de cada sprint; são suficientes para avaliar a capacidade de realizar sprints repetidos.

\section{Considerações finais}

Em linhas gerais, os testes para avaliação da capacidade de realizar sprints repetidos podem fornecer importantes parâmeros de desempenho, o que permite a elaboração de programas de treinamento para melhora da capacidade de 
realizar esforços máximos repetidamente e melhora da capacidade de recuperação entre os esforços, podendo assim, refletir diretamente no desempenho durante uma partida. Dessa forma, recomendamos a utilização do tempo médio e/ou tempo total como uma medida geral da capacidade de realizar sprints repetidos, o melhor tempo entre os sprints para avaliação da capacidade de realizar esforços máximos e as parciais de tempo dos sprints de cada atleta para identificar pontos de queda de desempenho no teste.

\section{Referências}

ABRANTES, C., MAÇÃS, V., SAMPAIO, J. Variation in Football Players' Sprint Test Performance Across Different Ages and Levels of Competition. Journal of Sports Science and Medicine, v.3, n.YISI 1, p.44-49. 2004. Disponível em: http://www.jssm.org/YISI/1/7/yisi1-7.htm. Acesso em: 08/10/2009.

AZIZ, A. R., M. CHIA, ET AL. The relationship between maximal oxygen uptake and repeated sprint performance indices in field hockey and soccer players. J Sports Med Phys Fitness, v.40, n.3, Sep, p.195-200. 2000. Disponível em: http://dx.doi.org/10.1007/s00421-005-1382-8. Acesso em: 08/10/2009.

AZIZ, A. R., S. MUKHERJEE, ET AL. Relationship between measured maximal oxygen uptake and aerobic endurance performance with running repeated sprint ability in young elite soccer players. J Sports Med Phys Fitness, v.47, n.4, Dec, p.401-7. 2007. Disponível em:

http://cat.inist.fr/ ?aModele=afficheN\&cpsidt=20032 416. Acesso em: 08/10/2009.

AZIZ, A. R., S. MUKHERJEE, ET AL. Validity of the running repeated sprint ability test among playing positions and level of competitiveness in trained soccer players. Int J Sports Med, v.29, n.10, Oct, p.833-8. 2008. Disponível em: http://dx.doi.org/10.1055/s-2008-1038410. Acesso em: 08/10/2009.

\section{BANGSBO, J. Entrenamiento de la condición física en el fútbol. Badalona: Paidotribo S.L. 2008}

BRADLEY, P. S., MASCIO, M. D., PEART D., OLSEN, P., SHELDON, B. High-Intensity Activity Profiles of Elite Soccer Players at Different Performance Levels. J Strength Cond Res, 2009. . Disponível em:

http://dx.doi.org/10.1519/JSC.0b013e3181aeb1b3. Acesso em: 07/10/2009.

CASTAGNA, C., ABT, G., MANZI, V., ANNINO, G., PADUA, E., D'OTTAVIO, S. Effect of recovery mode on repeated sprint ability in young basketball players. J Strength Cond Res. v.22, n.3, May, p.923-9. 2008. Disponível em: http://dx.doi.org/10.1519/JSC.0b013e31816a4281. Acesso em: 07/10/2009.

DUPONT, G., MILLET, G. P., GUINHOUYA, C., BERTHOIN, S. Relationship between oxygen uptake kinetics and performance in repeated running sprints. Eur J Appl Physiol. v.95, n.1, Sep, p.27-34. 2005. . Disponível em: http://dx.doi.org/10.1007/s00421-005-1382-8. Acesso em: 05/10/2009.

FERRARI BRAVO, D., IMPELLIZZERI, F. M. et al. Sprint vs. interval training in football. Int J Sports Med, v.29, n.8, Aug, p.668-74. 2008. Disponível em: http://dx.doi.org/10.1055/s-2007-989371. Acesso em: 10/10/2009.

GABBETT, T. J., MULVEY, M. J. Time-motion analysis of small-sided training games and competition in elite women soccer players. $\mathbf{J}$ Strength Cond Res. V.22, n.2, Mar, p.543-52. 2008. . Disponível em:

http://dialnet.unirioja.es/servlet/articulo?codigo $=26$ 52279. Acesso em: 12/10/2009.

GLAISTER M. Multiple-sprint work: methodological, physiological, and experimental issues. Int J Sports Physiol Perform. v.3, n.1, Mar, p.107-12. 2008. Disponível em: http://hk.humankinetics.com/lJSPP/viewarticle.cfm ?aid=15578. Acesso em: 09/10/2009.

GLAISTER, M., G. HOWATSON, et al. The reliability and validity of fatigue measures during multiple-sprint work: an issue revisited. J Strength Cond Res, v.22, n.5, Sep, p.1597-601. 2008. Disponível em: http://dx.doi.org/10.1519/JSC.0b013e318181ab80. Acesso em: 08/10/2009.

GLAISTER, M., STONE, M. H., ET AL. The reliability and validity of fatigue measures during short-duration maximal-intensity intermittent cycling. J Strength Cond Res, v.18, n.3, Aug, p.459-62. 2004. Disponível em:

http://journals.Iww.com/nscaiscr/Abstract/2004/08000/The Reliability and Vali dity of Fatigue Measures.11.aspx. Acesso em: 06/10/2009.

IMPELLIZZERI, F. M., MARCORA, S. M.. Test validation in sport physiology: lessons learned from clinimetrics. Int J Sports Physiol Perform, v.4, n.2, Jun, p.269-77. 2009. Disponível em: http://hk.humankinetics.com/lJSPP/viewarticle.cfm ?aid=17148. Acesso em: 05/10/2009.

IMPELLIZZERI, F. M., RAMPININI, E. et al. Validity of a repeated-sprint test for football. Int $\mathbf{J}$ Sports Med, v.29, n.11, Nov, p.899-905. 2008. 
Disponível em: http://dx.doi.org/10.1055/s-20081038491. Acesso em: 05/10/2009.

MECKEL, Y., O. MACHNAI, et al. Relationship among repeated sprint tests, aerobic fitness, and anaerobic fitness in elite adolescent soccer players. J Strength Cond Res, v.23, n.1, Jan, p.163-9. 2009.

http://dx.doi.org/10.1519/JSC.0b013e31818b9651. Acesso em: 08/10/2009.

MUJIKA, I., S. PADILLA, et al. Creatine supplementation and sprint performance in soccer players. Med Sci Sports Exerc, v.32, n.2, Feb, p.518-25. 2000. Disponível em:

http://journals.Iww.com/acsmmsse/pages/articleviewer.aspx? year=2000\&issue $\equiv 02000 \&$ article $=00039$ \&type $=$ abstract

OLIVER, J. L., ARMSTRONG, N., WILLIAMS, C. A. Relationship between brief and prolonged repeated sprint ability. J Sci Med Sport. V.12, n.1, Jan, p.238-43. 2009. Disponível em:

http://dx.doi.org/10.1016/i.jsams.2007.09.006.

Acesso em: 11/10/2009.

OLIVER, J. L. Is a fatigue index a worthwhile measure of repeated sprint ability? J Sci Med Sport, v.12, n.1, Jan, p.20-3. 2009. Disponível em: http://dx.doi.org/10.1016/j.jsams.2007.10.010. Acesso em: 11/10/2009.

OLIVER, J. L., WILLIAMS, C. A., ARMSTRONG, N. Reliability of a Field and Laboratory Test of Repeated Sprint Ability. Pediatric Exercise

Science, v.18, p.339-350. 2006. Disponível em: http://hk.humankinetics.com/PES/viewarticle.cfm? aid=6035. Acesso em: 08/10/2009.

PSOTTA, R., BUNC V. Reliability and validity of the Intermittent Anaerobic Running Test

(IAnRT). Science and Football V: The

Proceedings of the Fifth World Congress on Science and Football. Lisbon: Routledge, 2003. p.112-121.

RABELO, F. N., PASQUARELLI B. N., STANGANELLI L. C. R., DOURADO A. C. Correlação entre a capacidade de realizar sprints repetidos, velocidade linear e resistência aeróbia em futebolistas da categoria junior. Revista

Ciência Online, v.3, n.2, p.356-365. 2009.

RAMPININI, E., BISHOP, D., MARCORA, S. M., BRAVO, D. F., SASSI, R., IMPELLIZZERI, F. M. Validity of Simple Field Tests as Indicators as Match-Related Physical Performance in Top-Level Professional Soccer Players. Int J Sports Med, v.28, n.3, p.228-235. 2007. Disponível em: http://dx.doi.org/10.1055/s-2006-924340. Acesso em: 09/10/2009.
REILLY, T. Assessment of sports performance with particular reference to field games. Eur $\mathrm{J}$ Sports Sci, v.1, n.3, p.1-12. 2001. Disponível em: http://dx.doi.org/10.1080/17461390100071306. Acesso em: 10/10/2009.

SPENCER, M., BISHOP, D., DAWSON, B., GOODMAN, C. Physiological and metabolic responses of repeated-sprint activities:specific to field-based team sports. Sports Med. v.35, n.12, p.1025-44. 2005. Disponível em: http://adisonline.com/sportsmedicine/Abstract/200 5/35120/Physiological and Metabolic Responses of.3.aspx. Acesso em: 10/10/2009.

WRAGG, C. B., N. S. MAXWELL, et al. Evaluation of the reliability and validity of a soccer-specific field test of repeated sprint ability. Eur J Appl Physiol, v.83, n.1, Sep, p.77-83. 2000. Disponível em: http://dx.doi.org/10.1007/s004210000246. Acesso em: 09/10/2009.

ZAGATTO, A. M., W. R. BECK, et al. Validity of the running anaerobic sprint test for assessing anaerobic power and predicting short-distance performances. J Strength Cond Res, v.23, n.6, Sep, p.1820-7. 2009. Disponível em: http://dx.doi.org/10.1519/JSC.0b013e3181b3df32. Acesso em: 12/10/2009.

Endereço:

Henrique Bortolotti

Depto. de Educação Física - UEL

Rodovia Celso Garcia Cid, Pr 445 Km 380

Campus Universitário, Cx. Postal 6001

Londrina PR Brasil

86051-990

e-mail: hbortolotti@hotmail.com

Recebido em: 27 de novembro de 2009. Aceito em: 10 de maio de 2010.

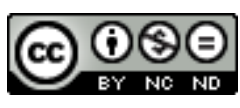

Motriz. Revista de Educação Física. UNESP, Rio Claro, SP, Brasil - elSSN: 1980-6574 - está licenciada sob Licenca Creative Commons 